\title{
The right way to write
}

\author{
Eyal Sheiner · Hans Ludwig
}

Received: 6 October 2008 / Accepted: 4 November 2008 / Published online: 27 November 2008

(C) Springer-Verlag 2008

\section{Introduction}

Research is a great way to improve scientific knowledge, to answer practical questions, establish medical protocols and in a round about way also improves your clinical skills. We all have to write articles. It is part of the MD or $\mathrm{PhD}$ requirements in several universities, medical schools, and it is always part of our promotion. In this editorial we will give several suggestions for writing a manuscript.

\section{Writing a manuscript}

Title

Attractive titles always draw more attention. Examples are: "Gender does matter" [1], "Caesarean section on demand-an ethical dilemma" [2], "Ultrasound in obstetrics: are we getting too good?" [3] If you want the readers to pay attention to the manuscript you can sure try it. Otherwise, the title might state the objective of the study, (i.e. "A retrospective study of unplanned out-of-hospital deliveries" [4]; "Third degree perineal tears in a university medical center where midline episiotomies are not performed" [5], "Ethics of human stem cells and cloning-a personal view" [6]) or sometimes give the highlight

\section{E. Sheiner $(\square)$}

Departments of Obstetrics and Gynecology,

Faculty of Health Sciences, Soroka University Medical Center,

Ben Gurion University of the Negev, P.O. Box 151,

Beer-Sheva, Israel

e-mail: sheiner@bgu.ac.il

H. Ludwig

Wartenbergstrasse 9, 4052 Basel, Switzerland instead, such as "Nuchal cord is not associated with adverse perinatal outcome" [7], or An elevated maternal plasma, but not amniotic fluid, soluble fms-like tyrosine kinase-1 (sFlt-1) at the time of mid-trimester genetic amniocentesis is a risk factor for preeclampsia [8].

\section{Introduction}

This section should give the background and the rationale for performing the study. This part needs to be an appetizer for the reader who then decides whether to keep on reading or skipping the article. Also, it should focus on the "so what?" question everybody has: does this study make my day different tomorrow?

This is not a section for your perspective, although the study hypothesis can be given and add some personal touch to the manuscript. Make sure to state the objective clearly. Unfortunately, from time to time we read articles with an objective that makes no sense, such as comparing pregnancy outcome in high versus low risk pregnancies. Finding that "high risk pregnancies are an increased risk for adverse perinatal outcome" will not be of interest to the readers. "Fishing expeditions" such as "I have all data let's see what we have now" are not interesting as well, and accordingly it is always better to concentrate on the new and insightful topic and not vast comparisons of variables.

\section{Case reports}

Most journals do not accept case reports any more. Impact factor is calculated as cites to recent articles divided by the number of recent articles. Most case reports are not cited and accordingly reduce the impact factor of the journal. On the contrary, letters to the editor are not calculated nor are 
editorials. There is no point in writing the "only" fifth reported case, and writing case reports make sense only if it is a real insightful case, and that other physicians can learn from it.

\section{Methods}

Methods should include the setting for the study, the design of the study, the subjects, the treatment or intervention, and the type of statistical analysis. If you have selected a group of exposed subjects and a group of non-exposed subjects and followed up both groups to compare the incidence of disease, do not call it a case-control study, but rather a cohort study. In a case control study we identify a group of individuals with the disease (i.e. cases) and a group of subjects without that disease will serve as the controls. Ask an epidemiologist or a statistician in data analysis if you are not fluent in this topic.

\section{Results}

This section includes the outcome of the study and statistical significance. Confirm that data are clearly presented in an easily readable form and that no unnecessary repetitions appear in the text and tables (eliminate tables presenting information that can easily be incorporated into the text). Make sure each table is titled, numbered, and typed on a separate page. Only standard, universally understood abbreviations should be used. Figures and graphs should be self-explanatory.

\section{Discussion}

The discussion section should discuss the major findings of the study. In this section you should state the significance of the results. Discuss what the insightful points you found were. Do not copy and paste from other articles regarding similar topics, but you can sure discuss differences between the studies. Point out the limitations of your study, and give implications, including further studies that are recommended.

\section{References}

Use programs such as Endnote or copy and past the references from the Medline. In such a way no mistakes will occur. Most journals ask for reviewers that published on the same subject and that are cited in your list. They will not like to see their name misspelled. Basically, references should not exceed 20-25 in number and should be updated and limited to the last decade, unless there is a true historical interest. References should accord with the system used in Uniform Requirements for Manuscripts Submitted to
Biomedical Journals. Use the Index Medicus abbreviations for journal titles, and make sure you do not write "the green journal" instead of "Obstet Gynecol".

What's next?

After you have all data, start writing. Write quickly, even start with ideas and make several drafts; remember that there is no perfect draft. Nevertheless, drafts are a basis for changes. Having said that, before submitting your article ensure that the article does not look like a draft, and that the "bride" is as pretty as can be. Revise the manuscript several times before submission. Think carefully about the author's list. Make sure you listed all contributors, and did not include undeserved authors. There are always deserved and un-deserved authorships and remember that nothing else wins or looses friends more rapidly. In several journals, however, you can not list more than six authors. If the article was written by more than one author, check that the style remains consistent throughout the manuscript. It is always good to target a specific journal to which you plan to submit the article. If it is a great article, the Archives of Gynecology and Obstetrics will be happy to consider it for publication.

Conflict of interest statement None.

\section{References}

1. Sheiner E, Levy A, Katz M, Hershkovitz R, Leron E, Mazor M (2004) Gender does matter in perinatal medicine. Fetal Diagn Ther 19(4):366-369. doi: 10.1159/000077967

2. Ludwig H, Loeffler FE (2001) Caesarean section on demand-an ethical dilemma. Arch Gynecol Obstet 264(4):169-170. doi:10.1007/ s004040000145

3. Abramowicz JS, Sheiner E (2006) Ultrasound in obstetrics: are we getting too good? Arch Gynecol Obstet 274(1):1-3. doi:10.1007/ s00404-005-0113-z

4. Sheiner E, Hershkovitz R, Shoham-Vardi I, Erez O, Hadar A, Mazor M (2004) A retrospective study of unplanned out-of-hospital deliveries. Arch Gynecol Obstet 269(2):85-88. doi:10.1007/ s00404-002-0426-0

5. Sheiner E, Levy A, Walfisch A, Hallak M, Mazor M (2005) Third degree perineal tears in a university medical center where midline episiotomies are not performed. Arch Gynecol Obstet 271(4):307310. doi:10.1007/s00404-004-0610-5

6. Ludwig H, Diedrich K (2002) Ethics of human stem cells and cloning-a personal view. Arch Gynecol Obstet 266(4):185-186. doi:10.1007/s00404-002-0335-2

7. Sheiner E, Abramowicz JS, Levy A, Silberstein T, Mazor M, Hershkovitz R (2006) Nuchal cord is not associated with adverse perinatal outcome. Arch Gynecol Obstet 274(2):81-83. doi:10.1007/ s00404-005-0110-2

8. Park CW, Park JS, Shim SS, Jun JK, Yoon BH, Romero R (2005) An elevated maternal plasma, but not amniotic fluid, soluble fmslike tyrosine kinase-1 (sFlt-1) at the time of mid-trimester genetic amniocentesis is a risk factor for preeclampsia. Am J Obstet Gynecol 193(3 Pt 2):984-989. doi:10.1016/j.ajog.2005.06.033 